\title{
Effects of Payment Timing and Prior Outcomes on the Composition of Choices over Public Lotteries
}

\author{
David Scrogin \\ Department of Economics, University of Central Florida, Orlando, USA \\ Email: dscrogin@ucf.edu
}

How to cite this paper: Scrogin, D. (2017) Effects of Payment Timing and Prior Outcomes on the Composition of Choices over Public Lotteries. Theoretical Economics Letters, 7, 747-756. https://doi.org/10.4236/tel.2017.74054

Received: April 17, 2017

Accepted: June 4, 2017

Published: June 7, 2017

Copyright $\odot 2017$ by author and Scientific Research Publishing Inc. This work is licensed under the Creative Commons Attribution International License (CC BY 4.0).

http://creativecommons.org/licenses/by/4.0/ (c) (i) Open Access

\begin{abstract}
This note investigates payment timing and prior outcome effects on individual choice under uncertainty using a two-year dataset containing more than 29,000 individual discrete choices over 128 annual lotteries for big-game (elk) hunting licenses in the southwest United States. In the first year, lottery applicants were required to prepay for licenses, and in the second year, the prepayment rule was removed, resulting in a more than twofold increase in the number of applicants. Results from nonparametric hypothesis tests indicate significant differences in the composition of lottery choices between new and prior applicants and between applicants who were drawn versus not drawn before the prepayment rule was removed. The findings contribute to experimental evidence that decisions made under uncertainty may be affected by the administrator's choice of payment mechanism and the subject's gains or losses from earlier choices.
\end{abstract}

\section{Keywords}

Prepayment, Prior Outcomes, Lottery Choice, Choice under Uncertainty

\section{Introduction}

Behavioral theories of individual decision-making have postulated that individual choices over alternatives with uncertain outcomes may be influenced by the timing in which individuals receive, or are required to make, compensatory payments and by the outcomes from prior choices. The hypotheses have been tested in several experimental settings, with evidence of significant payment timing and prior outcome effects consistently being identified. In laboratory studies in which subjects are paid for participating and for their performance across experimental tasks, [1], [2], and [3] found that "house money" effects 
coined by [4] may be induced when participation fees are paid upon completion of the experimental tasks, with riskier choices being made on average relative to when the fees are paid up front. And in repeated choice experiments, [1], [4], and [5] found the outcomes from prior choices may influence subsequent decisions and identified conditions under which less or more risk-averse behavior may result from early successes versus losses.

This note provides an out-of-lab investigation of the effects of payment timing and prior outcomes on individual choice under uncertainty using a unique dataset containing more than 29,000 individual choices over 128 annual lotteries for big-game (elk) hunting licenses in the southwest United States. Lottery-rationed hunting privileges allocated by state and provincial wildlife management agencies are common throughout North America (see e.g., [6] and [7]), and in addition to generating significant revenues for wildlife management and rural economies, the institutional arrangement provides a natural setting for investigating individual risky decision-making. The data evaluated here were collected from the state of New Mexico and span a two-year period over which the state wildlife management agency varied the timing in which lottery applicants were required to pay for a non-transferable license allowing the holder to harvest an elk within a specific wildlife management unit over a five-day period between October and March.

In the first year of the data, lottery applicants were required to prepay for licenses, and the fees were later refunded to applicants who were not randomly drawn. However, in the second year, the state removed the pre-payment rule, and resident applicants were ensured of receiving seventy-eight percent of the total licenses. ${ }^{1}$ While the effect of the license quota on the probability of being drawn was known to be largely ex ante neutral, removing the prepayment rule had a sharp effect on participation, with the number of applicants nearly tripling over the prior year. As the lottery data identifies individual applicants, their choices, and the outcomes (drawn or not drawn) in both years, the composition of lottery choices is investigated below across applicant groups and alternative measures of the probability of being drawn for evidence of payment timing and prior outcome effects on decision-making outside of the experimental lab.

The next section begins by reviewing the applicant data and constructing ex ante and ex post measures of the probability of being drawn in each of the 128 lotteries. The empirical distributions of lottery choices over the probability measures are then evaluated and results are presented from nonparametric hypothesis tests of the equality of the composition of lottery choices by individuals who participated in both years and individuals who only entered subsequent to the removal of the prepayment rule. The findings indicate that the sensitivity of new applicants to the prepayment rule does not necessarily correspond to the frequency with which high (or low) probability lotteries are chosen relative individuals who participated in both years. However, significant differences are

${ }^{1}$ Prepayment of the license fee by lottery applicants had been required for more than twenty years. In the period evaluated here the resident license fee ranged from $\$ 37$ to $\$ 60$. Additional details on the lottery characteristics are discussed in [7]. 
found in the composition of lottery choices between the group of applicants who was drawn in the prior year and the group of applicants who was not drawn. The empirical results complement experimental findings that choice under uncertainty may be influenced by the payment arrangement individuals confront and the realized gains or losses from prior risky choices.

\section{Analysis of Lottery Choices}

\subsection{The Data and Probability Measures}

Information on the composition of the lottery applicant data used in the analysis is reported in Table 1. The data contain about 11,000 resident applicants for elk licenses who participated in the year before and the year after the state removed the prepayment rule (1996-97 and 1997-98) and about 19,000 resident applicants who participated only after the rule was removed. To distinguish between the two applicant groups, the former will be referred to as "prior" applicants and the latter will be referred to as "new" applicants. Prior and new applicants differed in age by about three years on average, and about ninety-two percent of prior applicants were male versus about eighty-eight percent of new applicants. Considering prior applicants, about sixty percent were drawn in the year before removal of the prepayment rule, and less than half chose the same lottery in both years. Of those who chose the same lottery, about sixty percent were previously drawn versus about fifty percent of applicants who chose a different lottery after the rule changed.

While the total number of licenses to be awarded in each lottery is documented in the annual application book, the probability of being drawn is unknown ex ante. ${ }^{2}$ To assist applicants in choosing a lottery to enter, the book re-

Table 1. Summary statistics on lottery applicants and choices after removal of the prepayment rule.

\begin{tabular}{ccc}
\hline Applicant Characteristics & Prior Applicants & $\frac{\text { New Applicants }}{\mathrm{N}=11,024}$ \\
Average Age & $43.5(12.87)$ & $40.17(13.08)$ \\
\% Male & 92.3 & 88.4 \\
\% Drawn in Prior Year & 57.1 & - \\
\% Choosing Same Lottery & 46.3 & - \\
\% Drawn Prior Year & 61.4 & - \\
\% Not Drawn Prior Year & 38.6 & - \\
\% Choosing Different Lottery & 53.7 & - \\
\% Drawn Prior Year & 53.3 & - \\
\% Not Drawn Prior Year & 46.7 & - \\
\hline
\end{tabular}

Note: Standard deviations are reported in parentheses. The data were provided by the New Mexico Department of Game and Fish.

${ }^{2}$ The total number of licenses to be awarded ranged from 5 to 350 across the 128 lotteries in both years, and the average and median number of licenses awarded were 91.6 and 50, respectively. 
ports the total number of applicants in the preceding year, and after the prepayment rule was removed the state provided additional information to applicants by decomposing the total number of applicants in the previous year into resident and non-resident groups. From this information, two ex ante measures of the probability of being drawn are constructed for the analysis. The first (EAP1) is the probability of being drawn in the year before the rule changed and is equal to the total number of licenses to be awarded-which did not change between the years-divided by the total number of applicants in the prior year. The second ex ante probability measure (EAP2) is equal to the number of licenses to be awarded to residents (seventy-eight percent of the total licenses in each lottery) divided by the number of resident applicants in the prior year. In addition to the two ex ante probability measures, the realized ex post probability (EPP) is constructed from the applicant data as it identifies the number residents who applied after the payment rule changed. Therefore, the difference between EPP and EAP2 is that EPP reflects the realized number of resident applicants, whereas EAP2 reflects the number of resident applicants in the prior year.

The three measures of the probability of being drawn are summarized across the 128 lotteries in Figure 1, where EAP1, EAP2, and EPP appear along the horizontal axes. ${ }^{3}$ EAP1 and EAP2 are compared in the first panel, and EAP1 and EAP2 are compared against EPP in the second and third panels, respectively. The results in the first panel indicate the ex ante probability measures differ negligibly across the majority of the 128 lotteries, with the mean and median differences between EAP1 and EAP2 being 0.03 and 0.04, respectively. EAP1 ranges from 0.10 to 1 over the lotteries and has an average and median value of 0.56 and 0.51 , respectively. Similarly, EAP2 ranges from 0.09 to 1 and has an average and median value of 0.53 and 0.45 , respectively. In contrast, due to the large increase in applicants after the payment rule changed, the ex post probability of being awarded a license (EPP) is notably smaller than EAP1 and EAP2 over the majority of lotteries, as indicated in the second and third panels in Figure 1. EPP ranges from 0.03 to 1 and has an average and median value of 0.47 and 0.39 , respectively.
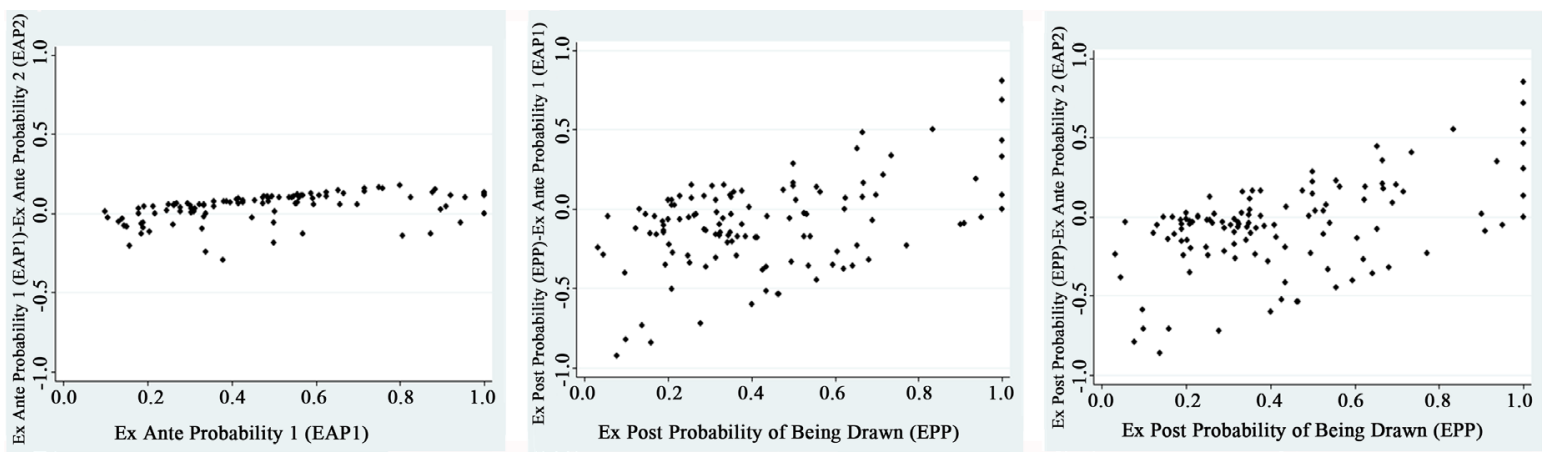

Figure 1. Differences between the ex ante and ex post probabilities of being drawn over 128 lotteries.

${ }^{3}$ Figure 1 and Figure 2 were generated in Stata version 12. 


\subsection{Analysis and Results}

To investigate the composition of lottery choices between new and prior applicants and between prior applicants who were drawn before the prepayment rule was removed versus those who were not drawn, the empirical distributions of lottery choices are reported in Figure 2, where EAP1, EAP2, and EPP appear along the horizontal axes. Considering the top row in the figure, across the three probability measures the empirical distribution of the lottery choices made by applicants who were not previously drawn lies above the distribution of new applicants, and the distribution of new applicants lies above that of applicants who were previously drawn. As a group, applicants who were not drawn prior to the removal of the prepayment rule chose low probability lotteries with greater $\mathrm{cu}$ mulative frequency than both new applicants and applicants who were not previously drawn. Recalling that the number of applicants more than doubled after the prepayment rule was removed, despite the sensitivity of new applicants to the rule change, the cumulative frequency with which they chose relatively low (or high) probability lotteries does not deviate sizably from that of prior applicants as a group.
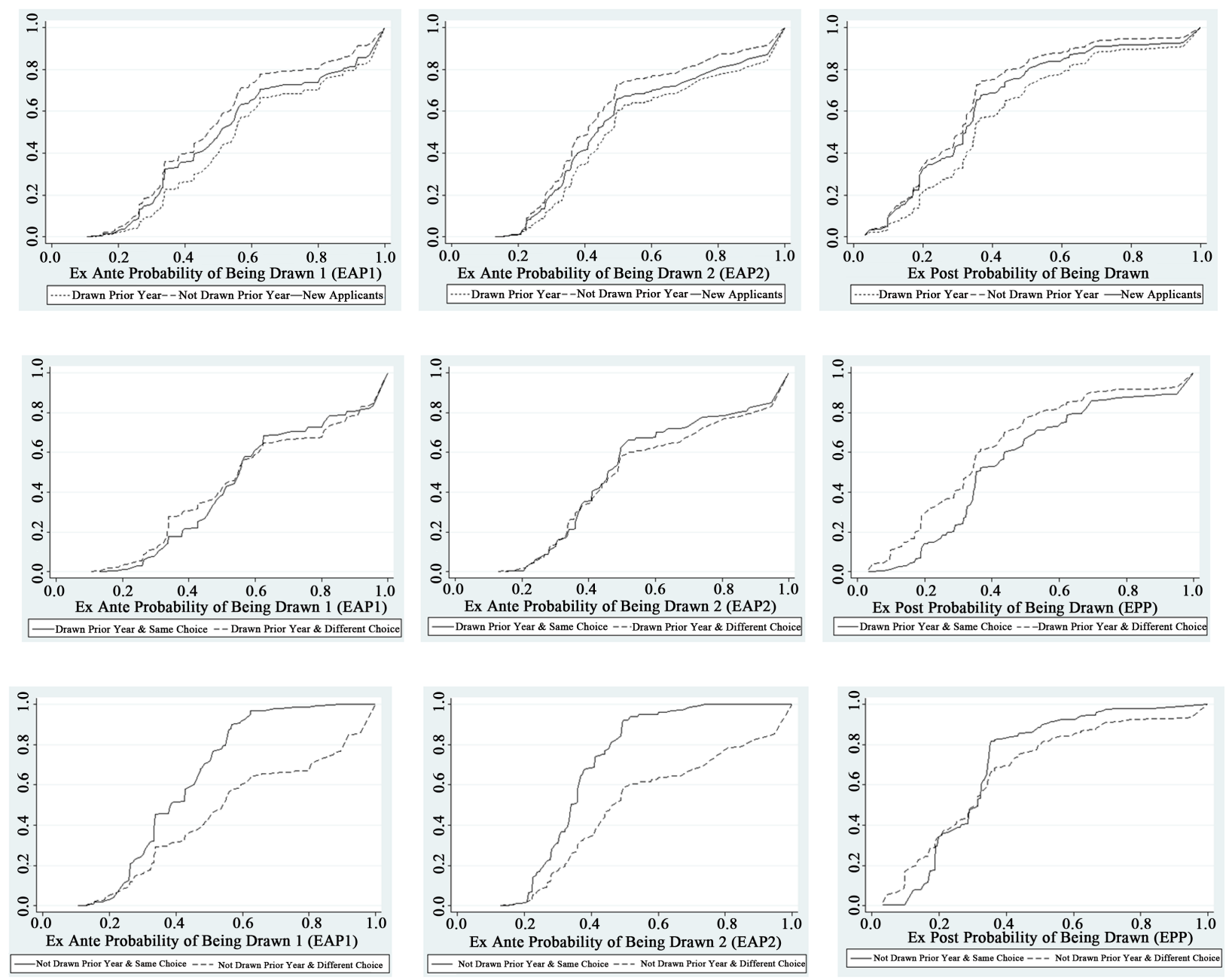

Figure 2. The empirical distributions of the composition of lottery choices by prior and new applicants. 
For comparison, note from the top row in Figure 2 about forty percent of applicants who were drawn before the payment rule changed subsequently chose lotteries with probabilities below the medians of EAP1 (0.51) and EAP2 (0.45) versus about fifty percent of new applicants and more than sixty percent of prior applicants who were not drawn before the rule changed. And considering the realized probability of being drawn (EPP) following the change in the rule, about fifty percent of applicants who were not previously drawn chose lotteries with probabilities below the median (0.39) versus about seventy percent of new applicants and about seventy-five percent of applicants who were not previously drawn. The results suggest that the random outcome from the prior year (drawn or not drawn) may influence applicant choices in the subsequent year, with applicants who were not previously drawn choosing lower probability lotteries with greater cumulative frequency than other groups of applicants.

To formally test for differences in the distributions of lottery choices between i) prior applicants and new applicants, ii) prior applicants who were previously drawn and prior applicants who were not previously drawn, and iii) new applicants and the latter two groups of prior applicants, nonparametric hypothesis tests are conducted using information from the empirical distributions reported in the top row of Figure 2. For each of the 128 lotteries the percentage of the total number applicants from the respective group is measured, and from this the cumulative percentage of applicants over the three measures of the probability of being drawn (EAP1, EAP2, and EPP) is measured. Differences in the distributions of the percentage of applicants and in the cumulative percentage of applicants are tested between the groups using Wilcoxon's matched-pair test for cases i and ii and Friedman's matched-group test for case iii. A detailed review of the testing procedures is contained in [8].

Results from the Wilcoxon and Friedman tests are reported in Table 2. The null that the distribution of the percentage of applicants is equal between new and prior applicants fails to be rejected by the Wilcoxon test. However, across EAP1, EAP2, and EPP significant differences are found between the cumulative percentage of new and prior applicants and between prior applicants who were

Table 2. Results of Wilcoxon and Friedman tests of the equality of the distributions of lottery choices by prior and new applicants.

\begin{tabular}{|c|c|c|c|c|c|c|}
\hline \multirow[b]{2}{*}{$\begin{array}{l}\text { Probability } \\
\text { Measure }\end{array}$} & \multicolumn{2}{|c|}{$\begin{array}{l}\text { Prior Year Applicants vs. } \\
\text { New Applicants }{ }^{\mathrm{a}}\end{array}$} & \multicolumn{2}{|c|}{$\begin{array}{l}\text { Drawn Prior Year vs. } \\
\text { Not Drawn Prior Year }\end{array}$} & \multicolumn{2}{|c|}{$\begin{array}{c}\text { Drawn Prior Year vs. } \\
\text { Not Drawn Prior Year vs. } \\
\text { New Applicants }{ }^{\mathrm{b}}\end{array}$} \\
\hline & $\begin{array}{c}\% \text { of } \\
\text { Applicants }\end{array}$ & $\begin{array}{l}\text { Cumulative \% } \\
\text { of Applicants }\end{array}$ & $\begin{array}{c}\% \text { of } \\
\text { Applicants }\end{array}$ & $\begin{array}{l}\text { Cumulative \% } \\
\text { of Applicants }\end{array}$ & $\begin{array}{c}\% \text { of } \\
\text { Applicants }\end{array}$ & $\begin{array}{c}\text { Cumulative } \\
\% \text { of Applicants }\end{array}$ \\
\hline EAP1 & 0.88 & $4.82^{*}$ & $9.88^{*}$ & $9.42^{*}$ & $359.51^{*}$ & $375.09^{*}$ \\
\hline EAP2 & 0.88 & $4.93^{*}$ & $9.88^{*}$ & $9.48^{*}$ & $359.51^{*}$ & $375.72^{*}$ \\
\hline EPP & 0.88 & $9.69^{*}$ & $9.88^{*}$ & $9.72^{*}$ & $359.51^{*}$ & $377.07^{*}$ \\
\hline
\end{tabular}

Note: ${ }^{a}$ Wilcoxon test. ${ }^{b}$ Friedman test. Test statistics are reported in absolute value. ${ }^{*}$ denotes significance at the $1 \%$ level. 
previously drawn and who were not previously drawn. Results from the Friedman test also indicate significant differences in the distribution of the percentage of applicants and in the cumulative percentage of applicants across the three groups at the one percent level across the three probability measures.

One interpretation of the results is that applicants who were previously drawn were more averse to the risk of not being drawn in the subsequent year than those who were not previously drawn. This may be because although an awarded license provides the holder with the opportunity to harvest in elk, the majority of applicants who are drawn do not do so, either because they are unsuccessful or they forego the hunt. Though the data do not identify whether individual license holders were successful, harvest statistics provided by the state indicate the proportion of license holders who were successful ranged from 0 to 1 across the 128 hunts, with average and median harvest rates of 0.37 and 0.30 , respectively. Together with the uncertainty of being drawn, it follows that unsuccessful efforts and expenditures put forth previously may be considered losses which are partially mitigated against in future periods by choosing lotteries with greater probabilities of success, all else constant.

In addition to the comparisons of new and prior applicants and of prior applicants who were previously drawn and who were not previously drawn, recall from Table 1 that more than half of prior applicants chose different lotteries after the prepayment rule was removed, and about half of the group was previously drawn. Alternatively, of those who chose the same lottery in both years, more than sixty percent were drawn in the year before the prepayment rule was removed. As all applicant groups confronted the same payment arrangement, and assuming individuals chose to enter their most-preferred lottery, the results from Table 1 suggest the prior year's random outcome (drawn or not drawn) may have influenced applicant choices in the subsequent year.

To further investigate the prior-outcome effect, applicants who were drawn in the year before removal of the prepayment rule are decomposed into groups who chose the same lottery in both years and who switched lotteries after the rule was removed. Similarly, applicants who were not previously drawn are decomposed into same-choice and different-choice groups. The empirical distributions are reported across EAP1, EAP2, and EPP in the second row of Figure 2 for same-choice and different-choice applicants who were previously drawn, and the third row of Figure 2 reports the empirical distributions for same-choice and different choice applicants who were not previously drawn. Considering applicants who were previously drawn, the distributions of the composition of lottery choices by same-choice and different-choice applicants consistently overlap across the ex ante probability measures (EAP1 and EAP2), whereas when measured by the realized probability of being drawn (EPP), the group of applicants who switched lotteries chose low probability lotteries with greater cumulative frequency than those who applied to the same lottery in both years.

Alternatively, from the third row of Figure 2 note that sizable differences are observed between the distributions of lottery choices by same-choice and differ- 
ent-choice applicants who were not previously drawn. About eighty percent of same-choice applicants who were not previously drawn chose lotteries with probabilities below the medians of EAP1 (0.51) and EAP2 (0.45) versus only about forty percent of the other applicant groups. And considering the realized probability of being drawn (EPP) after removal of the prepayment rule, about fifty percent of applicants who were not previously drawn chose lotteries with probabilities below the median (0.39) versus about seventy percent of new applicants and about seventy-five percent of applicants who were not previously drawn.

Similar to testing for differences in the composition of lottery choices between new and prior applicants (Table 2), Wilcoxon and Friedman tests are performed between the same-choice and different-choice sub-groups of prior applicants who were i) previously drawn and ii) not previously drawn using information from the empirical distributions that appear in the bottom row of Figure 2. The outcomes of the tests are summarized across the three probability measures in Table 3. Measured either by the percentage of applicants in each lottery or the cumulative percentage over the 128 lotteries ordered by EAP1, EAP2 or EPP, the test results indicate significant differences between the distribution of samechoice and different-choice applicants regardless of whether they were drawn or not drawn prior to the removal of the prepayment requirement.

For completeness, and as a final comparison of distributional differences between groups, Table 3 reports the test statistics from Friedman test. The results indicate across the three probability measures the distributions of the percentage of applicants and of the cumulative percentage of applicants jointly differ between the applicant groups at the one percent level. Collectively, when the composition of lottery choices is measured by the cumulative percentage of applicants across lotteries, the results in Table 2 and Table 3 indicate significant differences between the distributions of prior and new applicants. The effect of removing the prepayment rule was then twofold as the number of applicants more than doubled and the composition of lottery choices made by new applicants differed significantly from those willing to enter under either payment regime.

Table 3. Results of Wilcoxon and Friedman tests of the equality of the distributions of lottery choicesby prior applicants.

\begin{tabular}{|c|c|c|c|c|c|c|}
\hline \multirow[b]{2}{*}{$\begin{array}{l}\text { Probability } \\
\text { Measure }\end{array}$} & \multicolumn{2}{|c|}{$\begin{array}{l}\text { Drawn Prior Year } \\
\text { Same Choice vs. } \\
\text { Different Choice }^{\mathrm{a}}\end{array}$} & \multicolumn{2}{|c|}{$\begin{array}{c}\text { Not Drawn Prior Year } \\
\text { Same Choice vs. } \\
\text { Different Choice }^{\mathrm{a}}\end{array}$} & \multicolumn{2}{|c|}{$\begin{array}{l}\text { Drawn \& Same Choice } \\
\text { vs. Drawn \& Different } \\
\text { Choice vs. Not Drawn \& } \\
\text { Same Choice vs. Not Drawn } \\
\text { \& Different Choice }{ }^{\mathrm{b}}\end{array}$} \\
\hline & $\begin{array}{c}\% \text { of } \\
\text { Applicants }\end{array}$ & $\begin{array}{l}\text { Cumulative \% } \\
\text { of Applicants }\end{array}$ & $\begin{array}{c}\% \text { of } \\
\text { Applicants }\end{array}$ & $\begin{array}{l}\text { Cumulative \% } \\
\text { of Applicants }\end{array}$ & $\begin{array}{c}\% \text { of } \\
\text { Applicants }\end{array}$ & $\begin{array}{c}\text { Cumulative } \\
\% \text { of Applicants }\end{array}$ \\
\hline EAP1 & $7.66^{*}$ & $4.39^{*}$ & $3.16^{*}$ & $7.95^{\star}$ & $378.52^{*}$ & $522.97^{*}$ \\
\hline EAP2 & $7.66^{*}$ & $4.16^{*}$ & $3.16^{*}$ & $8.25^{*}$ & $378.52^{*}$ & $525.44^{*}$ \\
\hline EPP & $7.66^{*}$ & $9.40^{*}$ & $3.16^{*}$ & $2.974^{*}$ & $378.51^{*}$ & $528.29^{*}$ \\
\hline
\end{tabular}

Note: ${ }^{\mathrm{a} W i l c o x o n}$ test. ${ }^{\mathrm{b}}$ Friedman test. Test statistics are reported in absolute value. ${ }^{*}$ denotes significance at the $1 \%$ level. 


\section{Conclusions}

This note investigated the effects of relaxing prepayment rules imposed upon individuals and of the outcomes of prior choices on individual decision-making under uncertainty in a setting outside of the experimental lab. Using a rich data set containing more than 29,000 individual choices and associated outcomes from the state of New Mexico's annual lotteries for big-game (elk) hunting licenses, the composition of lottery choices made by various applicant groups was evaluated subsequent to the state's removal of a rule requiring applicants to prepay for licenses. Data on individual choices over lotteries for rationing publicly managed resources has been used for nonmarket demand analysis and benefits estimation, and this note demonstrated how such data can be analyzed for evidence of payment timing and prior outcome effects documented in several experimental studies. Results of the analysis indicate lottery participation was highly responsive to the removal of the prepayment rule, and across subjective and objective measures of the probability of being drawn in each of the 128 annual lotteries, significant differences were found in the composition of the lottery choices between new and prior applicants and between applicants who were previously drawn versus those who were not previously drawn. The results contribute to experimental findings that individual choice under uncertainty may be affected by the payment arrangement individuals confront and the realized gains or losses from previous risky choices.

As a final consideration, from a public policy perspective, although the total number of licenses rationed through the lottery did not change between the periods, the state's removal of the prepayment requirement seemingly reduced a financial burden for some members of the population. In doing so, however, the state bore the burden of processing thousands of additional applications. Furthermore, institutional rules did not require applicants who were drawn to purchase a license. That is, there were no penalties if individuals did not post-pay for awarded licenses. As a result, while ninety-seven percent of prior applicants purchased awarded licenses, only ninety percent of new applicants did so. Given that new applicants exceeded the number of prior applicants by more than twofold and were the majority recipients of licenses over the state's big-game hunting lotteries, the state was left with hundreds of unsold licenses which it was then confronted with allocating in some manner, and it did so by queue on a first-come first-served basis. The state subsequently reimposed the prepayment rule in the following year and to date, it remains in place.

\section{Acknowledgements}

I am grateful for the assistance in data collection provided by the New Mexico Department of Game and Fish and the helpful comments provided by two anonymous reviewers that improved several aspects of the paper. Any errors are my own.

\section{References}

[1] Davis, L.R., Joyce, B.P. and Roelofs, M.R. (2010) My Money or Yours: House Money 
Payment Effects. Experimental Economics, 13, 189-205. https://doi.org/10.1007/s10683-010-9235-7

[2] Hochman, G., Ayal, S. and Ariely, D. (2014) Keeping Your Gains Close but Your Money Closer: The Prepayment Effect in Riskless Choices. Journal of Economic Behavior and Organization, 107, 582-594.

[3] Xue, L., Sitzia, S. and Turocy, T.L. (2017) Mathematics Self-Confidence and the "Prepayment Effect" in Riskless Choice. Journal of Economic Behavior and Organization, 135, 239-250.

[4] Thaler, R.H. and Johnson, E.J. (1990) Gambling with the House Money and Trying to Break Even: The Effects of Prior Outcomes on Risky Choice. Management Science, 36, 643-660. https://doi.org/10.1287/mnsc.36.6.643

[5] Weber, M. and Zuchel, H. (2005) How Do Prior Outcomes Affect Risk Attitude? Comparing Escalation of Commitment and the House-Money Effect. Decision Analysis, 2, 30-43. https://doi.org/10.1287/deca.1050.0034

[6] Boxall, P.C. (1995) The Economic Value of Lottery-Rationed Recreational Hunting. Canadian Journal of Agricultural Economics, 43, 119-131.

https://doi.org/10.1111/j.1744-7976.1995.tb00111.x

[7] Scrogin, D. (2005) Lottery-Rationed Public Access under Alternative Tariff Arrangements: Changes in Quality, Quantity, and Expected Utility. Journal of Environmental Economics and Management, 50, 189-211.

[8] Hollander, M., Wolfe, D.A. and Chicken, E. (2014) Nonparametric Statistical Methods. 3rd Edition, John Wiley \& Sons, Inc., New York.

\section{Submit or recommend next manuscript to SCIRP and we will provide best} service for you:

Accepting pre-submission inquiries through Email, Facebook, LinkedIn, Twitter, etc. A wide selection of journals (inclusive of 9 subjects, more than 200 journals)

Providing 24-hour high-quality service

User-friendly online submission system

Fair and swift peer-review system

Efficient typesetting and proofreading procedure

Display of the result of downloads and visits, as well as the number of cited articles

Maximum dissemination of your research work

Submit your manuscript at: http://papersubmission.scirp.org/

Or contact tel@scirp.org 